\title{
Prevalence and pattern of menstrual disorders among school going adolescents in northern district of Kerala
}

\author{
Antherjanam S D. ${ }^{1 *}$, Karunakaran U. ${ }^{2}$, Jayasree A K. ${ }^{3}$, Antony R. ${ }^{4}$, Anitha S S. ${ }^{5}$, Harsha C H. ${ }^{6}$ \\ DOI: https://doi.org/10.17511/ijphr.2016.i3.04 \\ 1* Devaki Antherjanam S, Assistant Professor, Department of Community Medicine, Sree Narayana Institute of Medical Sciences, \\ Kunnukara, Kerala, India. \\ 2 Usha Karunakaran, Associate Professor, Department of Community Medicine, Academy of Medical Sciences, Pariyaram, Kerala, India. \\ 3 Jayasree A K, Professor, Depertment of Community Medicine, Academy of Medical Sciences, Pariyaram, Kerala, India. \\ ${ }^{4}$ Raju Antony, Professor, Department of Community Medicine, Sree Narayana Institute of Medical Sciences, Kunnukara, Kerala, India. \\ 5 Anitha S S., Assistant Professor, Department of Community Medicine, Academy of Medical Sciences, Pariyaram, Kerala, India. \\ 6 Harsha C H, Assistant Professor, Department of Biostatistics, Sree Narayana Institute of Medical Sciences, Kunnukara, Kerala, India.
}

Background: Adolescents face a range of health challenges, numerous information and guidance regarding adolescent health remaining ignored due to constraints at different levels of health system. One of the main problems among adolescent girls are irregular menstruation, excessive bleeding and dysmenorrhoea. Menstrual irregularities during adolescent period have association with reproductive morbidities in adulthood. Objective: To study the prevalence and pattern of menstrual disorders and its associated factors among IX to XII class adolescent girls in Kannur district. Methods: Cross-sectional study among school going adolescent Girls from class IX to XII in Kannur District. Results: Among the 1722 study participants, 48.8\% had menstrual disorders, in which dysmenorrhoea is the most common menstrual disorder reported $71.5 \%$. The risk factors like rural residence, lower socio-economic status, mixed diet, non-consumption of egg, not physically active both during routine life and also during menstruation, increased BMI showed a significant association with menstrual disorder among the study participants. Conclusion: Use of services by adolescents is limited may be due to lack of adequate privacy and confidentiality and judgemental attitudes of service providers, who often lack counselling skills. Therefore, effective services like assurance of confidentiality, psychological support, counselling is necessary.

Keywords: Adolescence, Menstrual disorder, School going

Corresponding Author

Devaki Antherjanam S, Assistant Professor, Department of Community Medicine, Sree Narayana Institute of Medical Sciences, Kunnukara, Kerala, India.

Email: drdevakianand@gmail.com
How to Cite this Article

Antherjanam S D, Karunakaran U, Jayasree A K, Antony R, Anitha S S, Harsha C H. Prevalence and pattern of menstrual disorders among school going adolescents in northern district of Kerala. Public Health Rev Int J Public Health Res. 2016;3(3):109118.

\section{Available From}

https://publichealth.medresearch.in/index.php/ijphr/ article/view/40
To Browse

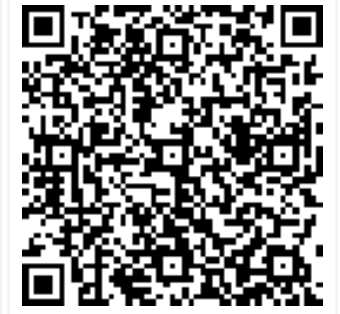

Manuscript Received 2016-05-16

Conflict of Interest No
Review Round 1 2016-05-28

Funding $\mathrm{Nil}$

Review Round 2
2016-06-11
Ethical Approval
Yes

Review Round 2

Yes
Review Round 3

Plagiarism X-checker $7 \%$
Accepted 2016-06-27

(c) 2016 by Devaki Antherjanam S, Usha Karunakaran, Jayasree A K, Raju Antony, Anitha S S., Harsha C H and Published by Siddharth Health Research and Social Welfare Society. This is an O'pen Access article licensed under a Creative Commons Attribution 4.0 International License https://creativecommons.org/licenses/by/4.0/ unported [CC BY 4.0]. 


\section{Introduction}

Adolescents face a range of health challenges, including malnutrition and anaemia, lack of knowledge on Sexual and Reproductive Health, substance misuse, communicable and noncommunicable diseases, injuries and violence. Numerous information and guidance regarding adolescent health remaining ignored due to constraints at different levels of health system [1].

The main problems faced by the adolescent girls are irregular menstruation, excessive bleeding and dysmenorrhoea. Due to dysmenorrhoea, disruption in social life and the adverse qualities of life such as sickness absenteeism (28-48\%), loss of physical activity, academic dissatisfaction, personal relationships, confidence and concentration are seen[2]. Menstrual irregularities during adolescent period have association with reproductive morbidities in adulthood.

A cross sectional study conducted among school adolescent girls of classes five to twelve in the District Wardha, Maharashtra, Central India in 2009 showed a result of $22.1 \%$ of the study subjects had a menstrual cycle of length longer than 35 days and $8.38 \%$ adolescents had a menstrual cycle length shorter than 21 days. Among them 390 (69.52\%) had a cycle length between 21 and 35 days [3].

Another study, a cross-sectional study of 194 unmarried female students studying in various degrees level classes from undergraduate and postgraduate institutions from Mysore city explained the results of $11.9 \%$ of the participants had menstrual cycle length irregularity [4].

The study done by Amita Singh et al at Rewa, showed that the prevalence of menstrual disorders like irregularity, prolonged menstrual bleeding, heavy menstrual bleeding and Polycystic Ovarian Diseases were $7.47 \%, 10.28 \%, 23.36 \%$ and $3.73 \%$ respectively [5].

The dysmenorrhoea, at times, the pain is severe enough that a girl has to miss school, college or her work. Dysmenorrhoea is the most common gynaecologic disorder among female adolescents, with a prevalence of $60 \%$ to $93 \%$. In the United States, dysmenorrhoea is the leading cause of recurrent short-term school absenteeism [5].

In a study in Morocco, menstrual pain was often cited as the main single cause of school absenteeism among adolescent girls [6].
In a cross-sectional study done by Santina et al, 389 post-menarcheal schoolgirls aged 13-19 years were selected using a cluster random sampling method. Of these 161 (41.4\%) were regularly or sometimes absent from school due to menstrual problems and 289 (74.3\%) experienceddysmenorrhoea. Dysmenorrhoea was significantly associated with missing school days ( $P$ $=0.03)[7]$.

A study done at SRM Medical College Hospital and Research Centre, Kanchipuram district on Prevalence of Premenstrual Syndrome and Dysmenorrhoea among Female Medical Students and its Association with College Absenteeism showed the prevalence of dysmenorrhoea was $51 \%$ and that of the pre-menstrual syndrome was $67 \%$. Severity of dysmenorrhoea has a strong association with school absenteeism $(p=0.005)$ [8].

Use of services by adolescents may be limited. Poor knowledge and lack of awareness are the main underlying factors. Service provision for adolescents is influenced by many factors. At the level of health system, lack of adequate privacy and confidentiality and judgemental attitudes of service providers, who often lack counselling skills, are barriers that limit access to services. Shortcomings in their professional trainings often result in service providers being unable and sometimes unwilling to deal with adolescents in an effective and sensitive manner. It is important to influence the health seeking behaviour of them as their situation will be central in determining India's health, mortality, and morbidity and population growth scenario. Therefore, effective services must be planned accordingly like assurance of confidentiality, psychological support, counselling.

This study aims to figure out the prevalence and pattern of menstrual disorder among adolescents, in a scenario where not much studies regarding the topic has been studied earlier. Targeting this age group with awareness and early correction of matters and misconceptions related to adolescent sexual reproductive health issues would enable these groups to move forward with their lives in confidence and thus help us to yield a healthy society and empowered youth ready to face the challenges of life further on.

Objectives: To study the prevalence and pattern of menstrual disorders and its associated factors among IX to XII class adolescent girls in Kannur district. 


\section{Materials and Methodology}

A School-based Cross-sectional study was conducted among school going adolescent Girls from class IX to XII in Kannur District from 1st July 2013 to 30th June 2014. For the study, Kannur district was divided into two strata: urban and rural. All the Municipalities were considered as urban and all the Panchayat were considered as rural. All the Municipalities and Panchayats were divided into 3 sub-strata. One school from each sub-stratum was randomly selected.

All girls/ mixed schools in Kannur District with IXXII classes were taken for the study. All the female students from class IX to XII were considered for the study. In Municipalities, there were 17 government schools, 12 aided schools, 9 unaided schools and in Panchayats, there were 66 government schools, 28 aided schools and 39 unaided schools. One school from each sub-stratum were randomly selected using random number table. In total, six schools were selected by this Stratified Random Sampling Method.

Sample size of 1670 participants were achieved according to the prevalence rate of menstrual disorder, in a study done at Thiruvananthapuram was $21.1 \%$ [9] and by considering $10 \%$ of relative precision and $10 \%$ non-response rate. All the study participants, who haveattained menarche and those whose parents given consent,were included in the study. The students who were not present even after 2 visits were excluded from the study.

Height measurement using stadiometers with a minimum reading of $0.5 \mathrm{~cm}$ and Weight measurement using standardized digital weighing scale of BGS-1219, maximum weight up to $150 \mathrm{~kg}$ and minimum difference that can be measured is of $100 \mathrm{gms}$.

A pre-tested, self-administered, semi-structured questionnaire which comprises socio-demographic information such as age, parents' employment, and economic status along with dietary habits, physical activities and its frequency, menstrual characteristics such as the cycle regularity, duration of menstrual bleeding in a cycle, the length of menstrual cycle, presence of dysmenorrhoea, menstrual hygiene.

A validated Malayalam questionnaire for students and parents were used. With the forwarding letter of District education officer (Kannur), permission from respective schools was taken for collecting data.
Permission from institutional ethical and research committees were obtained. Anonymity was maintained throughout the study. Students were asked to assess their menstrual cycle of last 6 months. Pilot testing: Pilot testing done in one school before the study. Questionnaire was modified and standardised as per the requirement. Health education classes were taken for all possible adolescent girls in these schools regarding menstrual disorders, menstrual hygiene, nutrition, and relevance of physical activity, reproductive and sexual health after the data collection.

Operational Definitions: School absence was defined as missing half a day class or complete day in a school due to menstruation. Polymenorrhoea, oligomenorrhoea, moderate and severe dysmenorrhoea were taken as menstrual disorders [10]. An infrequent, irregularly timed episodes of bleeding occurring at intervals of >35 days were taken as oligomenorrhoea. Frequent episodes of menstruation occurring at intervals of $<21$ days as polymenorrhoea [10].

Painful abdominal cramps during menstruation aredysmenorrhoea. Of it's the mild occurs only on the 1st day of menstrual cycle. It does not interfere with the daily routine. Moderate may last for 1st 2-3 days, often accompanied with some mild malaise, headache, diarrhoea etc. Severe - there is intense pain that lasts for 2-7 days and affects the daily routine [10]. Frequent GI symptoms are associated. Psychological problems like sexual abuse, rape and school phobia, personal or family problems may also to contribute to decrease threshold to pain.

Moderate-intensity activity means breathing harder and heart beat faster. b). Vigorous-intensity activity means heart rate increases and the person will not be able to say more than a few words without catching a breath [11]. To assess the obesity, body mass index (BMI) is used. Classification of BMI is Underweight <18.5, Normal range 18.5-22.9, Overweight 23.0-24.9, Obese $>25.0$ [12].

Data was entered in Microsoft excel 2007 and analysis was carried out using the Statistical Package for the Social Sciences (SPSS) version 12 software. Statistical measures like mean with standard deviation, frequencies and proportions were used to describe the results. Inferential statistics chi square, Fischer exact test were used to find the association. ' $p$ ' value less than 0.05 was considered significant. 


\section{Results}

The study included 1722 participants and they belong to age group 13-18 years (Table 1 ). The distribution of religion, residence, socio-economic status (S-E) is given in Table 1 . Mixed diet was followed by $65.3 \%$ and $34.7 \%$ were on vegetarian diet. Among study subjects, $30.4 \%$ were doing physical activity for $<3$ days in a week and $26.1 \%$ of them were doing it daily.
Among the study population, $67.1 \%$ of them are doing physical activity for less than 30minutes a day, $15.4 \%$ of them were doing physical activity for $30 \mathrm{~min}-1$ hours and $17.4 \%$ were used to do for more than an hour. Among the students who don't do physical activity during menstruation, 24.3\% reasoned they feel weakened during menstruation, $18.5 \%$ agreed that they have least interest and $16.5 \%$ avoid activities due to pain abdomen. The other associated factors related to menstrual disorders are given in Table 2.

Table-1: Distribution of general characteristics among the study population $(\mathbf{n = 1 7 2 2 )}$

\begin{tabular}{|c|c|c|c|}
\hline \multicolumn{2}{|c|}{ Variables } & \multirow[t]{2}{*}{ Frequency } & \multirow[t]{2}{*}{ Percentage $(\%)$} \\
\hline Age (years) Mean age: $15.6+1.23$ & 13 & & \\
\hline & 14 & 324 & 18.8 \\
\hline & 15 & 335 & 19.5 \\
\hline & 16 & 456 & 26.5 \\
\hline & 17 & 517 & 30 \\
\hline & 18 & 34 & 2 \\
\hline \multirow[t]{3}{*}{ Religion } & Hindu & 987 & 57.4 \\
\hline & Muslim & 671 & 38.9 \\
\hline & Christian & 64 & 3.71 \\
\hline \multirow[t]{2}{*}{ Residence } & Panchayats & 1421 & 82.5 \\
\hline & Municipality & 301 & 17.5 \\
\hline \multirow[t]{5}{*}{ S-E status } & Upper & 5 & 0.3 \\
\hline & Upper middle & 596 & 34.6 \\
\hline & Lower middle & 738 & 42.9 \\
\hline & Upper lower & 298 & 17.3 \\
\hline & Lower & 85 & 4.9 \\
\hline \multirow[t]{7}{*}{ Age of menarche (years) Mean age: $13.24+1.01$} & 10 & 10 & 0.6 \\
\hline & 11 & 34 & 2 \\
\hline & 12 & 370 & 21.5 \\
\hline & 13 & 617 & 35.8 \\
\hline & 14 & 508 & 29.5 \\
\hline & 15 & 179 & 10.4 \\
\hline & 16 & 4 & 0.2 \\
\hline
\end{tabular}

In the study, $48.8 \%$ of the study participants had menstrual disorders and rest of the $51.1 \%$ had not reported such disorders. And among the study participants $71.2 \%$ had dysmenorrhoea

Table-2: Distribution of other associated factors related to menstrual disorders among the study population

\begin{tabular}{|l|l|l|l|}
\hline \multicolumn{2}{|c|}{ Variables } & \multicolumn{1}{|c|}{ Frequency } & Percentage (\%) \\
\hline Duration of a cycle (days) & 3 & 36 & 2.0 \\
\cline { 2 - 5 } & 4 & 177 & 10.3 \\
\cline { 2 - 5 } & 5 & 444 & 25.8 \\
\hline & 6 & 409 & 23.8 \\
\cline { 2 - 4 } & 7 & 521 & 30.3 \\
\hline & 8 & 93 & 5.4 \\
\hline & 9 & 11 & 0.6 \\
\hline & 10 & 28 & 1.6 \\
\hline
\end{tabular}




\begin{tabular}{|c|c|c|c|}
\hline & 12 & 3 & 0.2 \\
\hline \multirow[t]{2}{*}{ Egg consumption } & Yes & 1355 & 78.7 \\
\hline & No & 367 & 21.3 \\
\hline \multirow[t]{2}{*}{ Fried food consumption } & Yes & 1693 & 97.9 \\
\hline & No & 29 & 2.1 \\
\hline \multirow[t]{2}{*}{ Physical activity } & Spending time & 1555 & 90.3 \\
\hline & Not spending time & 167 & 9.7 \\
\hline \multirow[t]{2}{*}{ Physical activity during menstruation } & Spending time & 573 & 36.8 \\
\hline & Not spending time & 982 & 63.2 \\
\hline \multirow[t]{4}{*}{ Body Mass Index } & Underweight & 747 & 43.4 \\
\hline & Normal & 771 & 44.8 \\
\hline & Overweight & 133 & 7.7 \\
\hline & Obese & 71 & 4.1 \\
\hline \multirow[t]{2}{*}{ School absenteeism during menstruation } & Yes & 634 & 36.8 \\
\hline & No & 1088 & 63.2 \\
\hline
\end{tabular}

The reasons for school absenteeism during menstruation were uncomfortable 9.0\%,discomfort in changing pad/cloth $4.1 \%$, intolerable pain $19.2 \%$, heavy bleeding $4.1 \%$.

\section{Figure-3: Pattern of Menstrual cycle among the study participants}

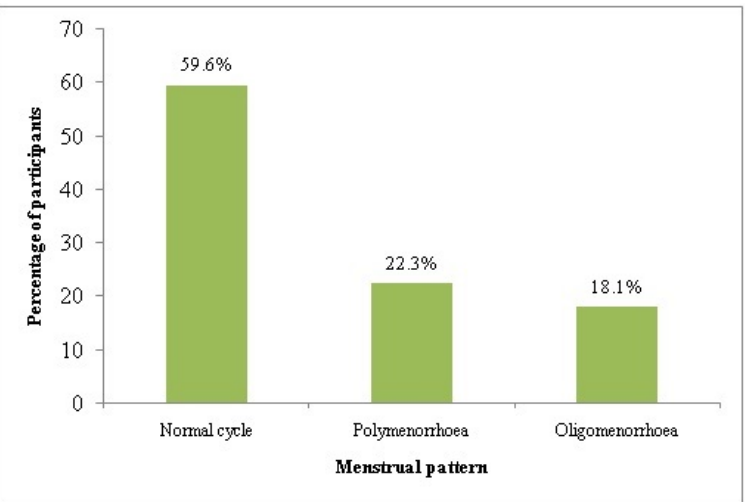

Table-3: Distribution of characteristics among study population with and without menstrual disorders

\begin{tabular}{|c|c|c|c|c|}
\hline Variables & $\begin{array}{l}\text { Without menstrual } \\
\text { disorder }(\%)\end{array}$ & $\begin{array}{l}\text { With menstrual } \\
\text { disorder }(\%)\end{array}$ & Total & $\stackrel{p}{\text { value }}$ \\
\hline \multicolumn{5}{|c|}{ Place of residence } \\
\hline Panchayats & $694(48.8)$ & $727(51.2)$ & 1421 & \multirow{2}{*}{$\begin{array}{l}<0.01 \\
* *\end{array}$} \\
\hline Municipality & $188(62.5)$ & $113(37.5)$ & 301 & \\
\hline \multicolumn{5}{|c|}{ Socio-economic status } \\
\hline Upper & $708(52.9)$ & $631(47.1)$ & 1339 & \multirow[t]{2}{*}{$0.01 *$} \\
\hline Lower & $174(45.4)$ & $209(54.6)$ & 383 & \\
\hline \multicolumn{5}{|l|}{ Diet } \\
\hline Mixed & $515(45.8)$ & $610(54.2)$ & 1125 & \multirow{2}{*}{$\begin{array}{l}<0.01 \\
* *\end{array}$} \\
\hline Vegetarian & $367(61.5)$ & $230(38.5)$ & 597 & \\
\hline
\end{tabular}

\begin{tabular}{|c|c|c|c|c|}
\hline Yes & $733(54.5)$ & $613(45.5)$ & 1346 & \multirow[t]{2}{*}{$<0.01 * *$} \\
\hline No & $149(39.6)$ & $227(60.4)$ & 376 & \\
\hline \multicolumn{5}{|l|}{ Physical activity } \\
\hline Spending time & $812(52.2)$ & $743(47.8)$ & 1555 & \multirow[t]{2}{*}{$\mid<0.01 * *$} \\
\hline Not spending time & $70(41.9)$ & $97(58.1)$ & 167 & \\
\hline \multicolumn{5}{|c|}{ Physical activity during menstruation } \\
\hline Spending time & $433(49.1)$ & $242(28.8)$ & 675 & \multirow[t]{2}{*}{$<0.01 * *$} \\
\hline Not spending time & $449(50.9)$ & $598(71.2)$ & 1047 & \\
\hline \multicolumn{5}{|c|}{ Basal Metabolic Index (BMI) } \\
\hline Underweight & $363(48.6)$ & $384(51.4)$ & 747 & \multirow[t]{4}{*}{$0.028 *$} \\
\hline Normal & $425(55.1)$ & $346(44.9)$ & 771 & \\
\hline Overweight & $60(45.1)$ & $73(54.9)$ & 133 & \\
\hline Obese & $34(47.9)$ & $37(52.1)$ & 71 & \\
\hline \multicolumn{5}{|l|}{ School absenteeism } \\
\hline Yes & $289(32.8)$ & $345(41.1)$ & 634 & \multirow[t]{2}{*}{$<0.01^{* *}$} \\
\hline No & $593(67.2)$ & $495(58.9)$ & 1088 & \\
\hline
\end{tabular}

In this study, majority belongs to the age group of 17 years, Hindus and lower middle class. Mean menarche age among the study sample was 13.24 1.01 and different factors like residence, S-E status, diet, egg consumption, physical activity, and physical activity during menstruation, Basal Metabolic Index, school absenteeism found to be statistically significant in the study (Table 3 ).

\section{Discussion}

In the present study, the mean age of the study population was $15.67+1.23$. The menarche age was found to be $13.24+1.01$ which is similar to many other studies. In the study at Mysore by Omidvar et al, the menarche age was $13.36+1.25$ years, study from West Bengal $13.06+1.43$ years, 
13.4 years in Goa study, 13.5 years in Chennai, 13.6 in East Delhi [4]. The menstrual disorders were $48.8 \%$ in the present study in which dysmenorrhoea is the most common menstrual disorder reported and among them $40.8 \%$ had irregular cycles.

Polymenorrhoea were reported by $22.3 \%$, while $18.1 \%$ had oligomenorrhoea. From the study subjects, $71.5 \%$ were suffering from dysmenorrhoea. This could be because of changing trends in lifestyle, dietary habit, stress, hormonal imbalance or some medical reasons which requires gynaecological assessment at the earliest.

The study results are almost similar to the result of study done in Maharashtra where $22.1 \%$ of them had oligomenorrhoea and $8.38 \%$ had Polymenorrhoea. But in Mysore study done by Omidvar et al menstrual irregularity was $11.9 \%$ with $6 \%$ had oligomenorrhoea, $2.2 \%$ had Polymenorrhoea and $78.2 \%$ had dysmenorrhoea [4].

Similar to the present study, a study done by Dambhare D G et al in Maharashtra showed a result of $69.52 \%$ had a cycle length between 21 and 35 days and $124(22.1 \%)$ longer than 35 days and $56.15 \%$ of dysmenorrhoea [3]. The study done by Amita Singh et al on adolescent girls a Rewa showed a result of $7.47 \%$ of menstrual disorder [5].

Dysmenorrhoea was the most prevalent menstrual problem with young women as in the study done by Santina et al in schoolgirls. They found $74.3 \%$ of dysmenorrhoea and it was significantly associated with missing school days [7]. In the present study, $41.1 \%$ of the study population with menstrual disorder had school absenteeism and the most common cause reported was 'intolerable pain abdomen during menstruation.

In a study done in Morocco, menstrual pain was often cited as the main single cause of school absenteeism among adolescent girls[6]. Several studies have shown that adolescents with primary dysmenorrhoea report that it effects their academic performance, social and sports activities and is a cause for school absenteeism [13].

Majority in the study follows mixed diet and egg consumption. In this study, the reduced egg consumption was significantly associated with menstrual disorder $(p=<0.01)$. Similar to it, Balbi $C$ et al also found that lower consumption of fish, eggs, and fruits are associated with dysmenorrhoea in adolescent girls [14].
The study found significant association between overweight and obesity with menstrual disorder $(p=0.028)$. But, in the study done by Fujiwara et al an increase in BMI is significantly associated with pre-menstrual syndrome $(p=0.035)$.

A study done by Yamamoto $\mathrm{K}$ et al among Japanese college students showed that the lower BMI, the higher the proportion of students who had experienced irregular menstrual cycles [15]. Similarly, in the present study also, menstrual disorder is more, $51.4 \%$, among people who had lower BMI and it is significantly associated $(p=0.01)$.

Among this study subjects, majority, $90.3 \%$ reported that they were physically active. The study found a significant association between physical activity and menstrual disorder $(p=<0.01)$. In a study done by $\mathrm{L}$. Bernstein et al found that the girls who engage in strenuous physical activity are often amenorrhoeic and have recently been reported to be at a reduced risk of breast cancer.

In their study, subjects who engaged in moderate physical activity had significantly shorter menstrual cycles [16]. And in the present study there is a highly significant association between physically active subjects and regular menstrual cycles $(p=0.004)$.

Among the $36.8 \%$ of school absentees during menstruation, $4.1 \%$ were due to discomfort in changing pad/cloth at school. Most of the studies have mentioned that, menstruation, sanitation and infrastructure of the school have a great impact on school attendance of girls. A 2005 study by UNICEF found that one in 10 African girls drop out of school upon reaching puberty or does not attend school during menstruation [1].

\section{Conclusion}

Majority of the adolescents with menstrual disorder in this study has dysmenorrhoea and among them majority of them belongs to lower socio-economic class. The study attempted to find a relation between various lifestyle factors like eating egg, fried food, and lack of physical activity, school absenteeism as these are the risk factors which are modifiable and intervention at this stage might result in healthier adults. Menstrual disorder was more among those who were not physically active and it was found to be more among those who avoid physical activity during menstruation. 
Menstrual disorder was more among overweight and obese adolescents in this study. Most of the people who consume egg did not have menstrual disorder and people who consume fried food also were not found to have menstrual disorder. School absenteeism due to menstruation was more among adolescents with menstrual disorder in the present study and the major reason which they pointed out was pain abdomen.

Use of services by adolescents are limited may be due to, at the level of health system, lack of adequate privacy and confidentiality and judgemental attitudes of service providers, who often lack counselling skills, are barriers that limit access to services. Therefore, effective services like assurance of confidentiality, psychological support, counselling is necessary. Initiatives like Adolescent Reproductive and Sexual Health Clinics (ARSHC) should be upheld and broaden the services.

\section{Limitations}

The current study has several limitations. First, as this study was based on a self-administered questionnaire. Second, this study was unable to reach the school drop-outs. This study had insufficient data to explain other menstrual disorders like Menorrhagia since the amount of bleeding were not able to assess and Metrorrhagia, since most of the study subjects may confuse it with oligomenorrhoea etc.

Importantly, this study has done to fill the gaps in areas related to menstruation within the literature. Secondly, a good number of samples from schools and the stratified random sampling of Kannur district in the study gave a good representation of the whole Kannur district.

\section{Acknowledgement}

First and foremost I thank God, the almighty for his blessings throughout my research work to complete it successfully. This study could not have been possible without the support and participation of students, their parents and teachers and authorities of the schools where the study was conducted. I find words inadequate to express my gratitude to $\mathrm{Dr}$ A. K. Jayasree, Professor and HOD, Department of Community Medicine, Academy of Medical Sciences, Pariyaram for permitting me to do this study and her constant encouragement, unreserved support and guidance throughout the study.
I am greatly indebted to my guide $\mathrm{Dr}$ Usha Karunakaran, Associate Professor of Department of Community Medicine, Academy of Medical Sciences, Pariyaram for her constant supervision and help, without which this work would not have materialized. I am thankful to Principal, Commodore (Dr.) M.J. John, SNIMS and Prof. (Dr.) Raju Antony, HOD Community Medicine, SNIMS for their moral support and guidance.

\section{Reference}

01. Olyai R ,Dutta D K. Recent advances in Adolescent Health. Jaypee publication. 2011;1st edition; 120-150.

[Crossref]

02. A Strategic Approach to Reporoductive, Maternal, Newborn, Child and Adolescent Health $(\mathrm{RMNCH}+\mathrm{A})$ in India. Ministry of Health \& Family Welfare Government of India. 2013.

[Crossref]

03. Dambhare DG, Wagh SV, Dudhe JY. Age at menarche and menstrual cycle pattern among school adolescent girls in Central India. Glob J Health Sci. 2012 Jan 1;4(1)105-11.

doi: $10.5539 /$ gjhs.v4n1p105 [Crossref]

04. Omidvar S, Begum K. Menstrual pattern among unmarried women from south India. J Nat Sci Biol Med. 2011 Jul;2(2)174-9. doi: $10.4103 / 0976-9668.92329$ [Crossref]

05. Singh A, Kiran D, Singh $H$, Nel B, Singh $P$, Tiwari $P$. Prevalence and severity of dysmenorrhea- $a$ problem related to menstruation, among first and second year female medical students. Indian J Physiol Pharmacol. 2008 OctDec;52(4)389-97.

[Crossref]

06. Andersch B, Milsom I. An epidemiologic study of young women with dysmenorrhea. Am J Obstet Gynecol. 1982 Nov;15;144(6)655-60.

Available from: [Article] [Crossref]

07. Santina T, Wehbe NF Ziade. Exploring dysmenorrhoea and menstrual experiences among Lebanese female adolescents. Eastern Meditarranean journal. 2012;18(8)857-863.

[Crossref] 
08. Lakshmi A, et al. Prevalence of Premenstrual Syndrome and Dysmenorrhoea among Female Medical Students and its Association with College Absenteeism. Int J Biol Med Res. 2011;2(4)1011-1016.

[Crossref]

09. Nair MK, Chacko DS, Ranjith Darwin M, Padma K, George B, P S R. Menstrual disorders and menstrual hygiene practices in higher secondary school girls. Indian J Pediatr. 2012 Jan;79(Suppl 1)S74-8.

doi: $10.1007 / \mathrm{s} 12098-011-0431-z \quad$ [Crossref]

10. Kumar D, Goel NK, Puri S, Pathak R, Sarpal SS, Gupta S, et al. Menstrual Pattern among Unmarried Women from Northern India. J Clin Diagn Res. 2013 Sep;7(9)1926-9.

Available from: [Article] [Crossref]

11. World Health Organisation. Global Recommendations On Physical Activity For Health. 2010.

Available form: [Article] [Crossref]
12. Park K. Textbook of Preventive and Social Medicine. 23rd Edition; Bhanot Publications. 620-635.

[Crossref]

13. Nag $U$, Kodali M. Meditation And Yoga As Alternative Therapy For Primary Dysmenorrhea. IJMPS. 2013;3(7)39-44.

[Crossref]

14. Balbi C, Musone R, Menditto A, Di Prisco L, Cassese E, D'Ajello M, Ambrosio D, Cardone1 A. Influence of menstrual factors and dietary habits on menstrual pain in adolescence age. Eur J Obstet Gynecol Reprod Biol. 2000 Aug;91(2)143-8.

[Crossref]

15. Douchi T, Kuwahata R, Yamamoto S, Oki T, Yamasaki H, Nagata Y. Relationship of upper body obesity to menstrual disorders. Acta Obstet Gynecol Scand. 2002 Feb;81(2)147-50. [Crossref]

16. Bernstein L, Henderson BE, Hanisch R, SullivanHalley J, Ross RK. Physical exercise and reduced risk of breast cancer in young women. J Natl Cancer Inst. 1994 Sep 21;86(18)1403-8.

[Crossref] 